\title{
EXPLORATION OF GOITROGENIC/ANTITHYROIDAL POTENTIALITY OF BAMBOO-SHOOTS IN RELATION TO THIOUREA
}

\author{
DEOTIMA SARKAR ${ }^{1}$, ARIJIT CHAKRABORTY ${ }^{1}$, CHANDRIMA BHATTACHARYA ${ }^{1}$, LAISHRAM HEMCHANDRA \\ SINGH $^{2}$, AMAR K. CHANDRA ${ }^{*}$
}

1Endocrinology and Reproductive Physiology Laboratory, Department of Physiology, University of Calcutta, 92, APC Road, Kolkata 700009, 2Department of Zoology (PG Section), D. M. College of Science, Imphal 795001 Email: physiology.ac@gmail.com

Received: 29 May 2017 Revised and Accepted: 31 Aug 2017

\section{ABSTRACT}

Objective: Natural goitrogens present in plant foods or antithyroidal drugs both alter the morphology and normal functional status of the thyroid gland interfering the synthesis and secretion of thyroid hormones. In this study, the goitrogenic potential of bamboo shoots (BS) containing natural goitrogens has been compared against a potent synthetic antithyroidal drug thiourea.

Methods: BS was fed to 6 rats by 1/3rdreplacement of 180grams (g) of their food i.e. $60 \mathrm{~g}$ of BS containing $35 \mathrm{~g}$ of goitrogens of cyanogenic origin such that each rat ideally consumed $6 \mathrm{mg} / 100 \mathrm{~g}$ of body weight per day and thiourea at a near equal dose of $6 \mathrm{mg} / 100 \mathrm{~g}$ of body weight per day was force fed to another 6 rats for a period of $45 \mathrm{~d}$. Changes in food consumption pattern, serum toxicity marker SGOT and SGPT, morphological changes like thyroid gland weight and histology and functional aspects like TPO activity, Na+-K+ATPase activity, urinary iodine excretion and serum T3,T4 and TSH levels induced by this natural and synthetic agent respectively were investigated. Results analyzed by ANOVA followed by post hoc tests.

Results: Food consumption pattern was similar in all groups while serum toxicity markers SGOT, SGPT showed a non-significant increase in experimental groups. Increase in body and thyroid gland weight as compared to control was seen on treatment with both antithyroidal agents, a greater percentage of increase was seen in thiourea treated group. TPO activity, Na+-K+ATPase activity, serum T3 and T4 levels were decreased significantly in both treated groups as compared to normal, with maximum inhibition in the thiourea treated group. Histological plates of BS treated thyroid revealed hypertrophy and thyroid follicular cell disruption with microcytic infiltration. Thiourea treated gland histological plate revealed complete abolition of normal histoarchitecture with marked changes in colloidal area and hyperplasia with folding and papillae on the epithelium.

Conclusion: In overall, the data indicate that though the goitrogenic potentiality of BS cannot be considered having similar efficacy to that of thiourea but as a food entity by itself, it has potent antithyroidal activity even in presence of adequate iodine intake.

Keywords: Dietary goitrogen, Thyroid, Thiourea, Bamboo-shoots, Thyroid peroxidase

(C) 2017 The Authors. Published by Innovare Academic Sciences Pvt Ltd. This is an open access article under the CC BY license (http://creativecommons.org/licenses/by/4.0/) DOI: http://dx.doi.org/10.22159/ijpps.2017v9i10.20332

\section{INTRODUCTION}

Thiourea is an established antithyroid agent whose derivatives form commercially available drugs like methimazole, carbamizole and propylthiouracil (PTU), etc [1]. Several other derivatives including ethylene thiourea (ETU) occur in fungicides, cigarette smoke and as primary work reagents in rubber industries [2]. Thiourea causes disruption of peroxidase activity in the thyroid gland leading to inhibition of thyroid hormone production and in animal testing has produced thyroid hyperplasia, decreased serum thyroxine levels and increased thyroid stimulating hormone (TSH) level [3]. However, prolonged exposure has reportedly resulted in thyroid follicular cell adenomas, carcinomas, liver and pituitary tumours. Several other side effects like gastrointestinal disorders, blood corpuscles disorders, raised the temperature and reproductive disorders have been associated with usage of such drugs [4].

Bamboo-Shoots (BS) in contrast to the synthetic drug thiourea is a natural goitrogenic cruciferous vegetable which is consumed almost as a staple food in the eastern regions of the world and causes endemic goitre in the North Eastern regions of India, where it is consumed mostly on a regular basis [5]. Its chemical analysis has revealed it to contain several anti-thyroidal constituents like cyanogenic glycosides, glucosinolates and thiocyanate around 600 $\mathrm{mg} / \mathrm{kg}$ wet weight on the whole [6]. Previous studies have also revealed its ability to inhibit peroxidase activity of thyroid, however, its exact mode of action is yet to be described [7]. Divergent to the side effects of thiourea, BS is actually gaining popularity for its many health benefits comprising improvement of cholesterol risks, cardiovascular disorders and anti-carcinogenic effects.
Although separately known for their antithyroid effects, a comparative analysis of the goitrogenic potential of such a natural goitrogen against an established antithyroid drug is not available. Rationality of this study is to establish the antithyroidal potentiality of BS in contrast to thiourea, reinforcing a comparative analysis of their thyroid disrupting potentiality.

\section{MATERIALS AND METHODS}

\section{Experimental design}

For the investigation, eighteen adult female rats (six as thiourea fed animals, six as BS fed animals and six as control animals) of $90 \pm 10 \mathrm{~g}$ body weight were used. The animals were obtained from M/S Chakraborty Enterprise, Kolkata, registered breeder vide Registration Number 1443/PO/b/11/CPCSEA and maintained as per national guidelines and protocols as approved by the Institutional Animal Ethics Committee (IAEC) number-IAEC/PG Project/Endo Special/2014. They were housed in three cages having six each; in air-conditioned rooms maintaining twelve hours light/twelve hours dark cycles. The rats had free access to drinking water and were fed on standardized normal laboratory diet $(20 \%$ protein) which consisted of $70 \%$ wheat, $20 \%$ Bengal gram, $5 \%$ fish meal powder, $4 \%$ dry yeast powder, $0.75 \%$ refined til oil and $0.25 \%$ shark liver oil [8]. BS was fed to 6 rats by $1 / 3$ rd replacement of $180 \mathrm{~g}$ of their food, such that $60 \mathrm{~g}$ of BS containing $35 \mathrm{mg}$ of goitrogens of cyanogenic origin (cyanogenic glucosides, glucosinolates and thiocyanate) was available at an ideal amount of $6 \mathrm{mg} / 100 \mathrm{~g}$ of body weight per rat and thiourea at a near equal dose of the antithyroid constituents of BS at $6 \mathrm{mg} / 100 \mathrm{~g}$ of body weight was force-fed to another 6 rats for a period of $45 \mathrm{~d}$. This is much below the oral LD50 for thiourea at 12 
$\mathrm{mg} / 100 \mathrm{~g}$ [9] and lies in the range of daily maintenance dose of hyperthyroid drug intake of $5 \mathrm{mg}-15 \mathrm{mg}$ per day [10].

\section{Chemicals and reagents}

Chloroform, Potassium Iodide (KI), Hydrogen Peroxide $\left(\mathrm{H}_{2} \mathrm{O}_{2}\right)$, Sodium Chloride (NaCl), Potassium Chloride (KCL), Sodium Dodecyl Sulphate (SDS) were purchased from Sisco Research Laboratories (SRL), Mumbai, India; bovine serum albumin (BSA), Magnesium Chloride $\left(\mathrm{MnCl}_{2}\right)$,TrisATP, ouabain were purchased from Sigma Chemical Company. T4 and T3 kits were purchased from RFCL Limited, India. TSH kits were purchased from Cusabio Biotech Limited. SGOT and SGPT kits were purchased from BBI solution (Cardiff, UK).

\section{Preparation of bamboo shoot containing food}

The experimental group of rats was fed bamboo shoots by replacing a $1 / 3$ rd portion of the normal diet. Sixty grams of bamboo shoots was weighed, equal amount of water was added to it and boiled for $15 \mathrm{~min}$. It was then mixed with 180 grams of normal food as mentioned [8].

\section{Food consumption pattern}

Food consumption of each rat per day was recorded daily during the period of treatment.

Calculation of food consumption for each rat (g/rat/day) was calculated as:

Food given (g)-Food wasted(g)=food consumption(g)

Sacrifice of the animal, body and thyroid weight

The animals were sacrificed on the consecutive day of the last treatment following Institutional Animal Ethics protocol of the Department of Physiology, University of Calcutta. Blood was collected from the hepatic portal vein of each animal and stored separately. Before sacrifice, the body weight of each rat was taken. The thyroid gland from each animal was collected, weighed and stored separately.

\section{Estimation of SGOT (Serum glutamic-oxaloacetic transaminase)} and SGPT (Serum glutamic pyruvic transaminase) activities

The enzymatic kit of BBI solution (Cardiff, UK) was used to estimate SGOT and SGPT activities following the manufacturer's protocol.

\section{Measurement of thyroid peroxidase (TPO) activity}

TPO was measured following the method of Alexander [11]. Thyroid glands from sacrificed animals were pooled (about $5 \mathrm{mg}$ ) and homogenized in a homogenizing tube containing $3-5 \mathrm{ml}$ phosphate buffer (pH-7.4, $5 \mathrm{mmol}$ ). The mixture was homogenized for 30-45 secs at $4{ }^{\circ} \mathrm{C}$ in glass homogenizer of Potter-Elvehjem, Germany. The homogenate was transferred and centrifuged at $4^{\circ} \mathrm{C}$ at $1000 \mathrm{rpm}$ for $10 \mathrm{~min}$ to separate cell debris and obtain mitochondrial fraction. The supernatant was collected and utilized to measure the TPO activity. Peroxidase activity was determined using potassium iodide substrate (KI). The reaction mixture $(2 \mathrm{ml})$ contained $50 \mathrm{mmol} / \mathrm{lit}$ $\mathrm{KI}, 0.33 \mathrm{mmol} / \mathrm{lit} \mathrm{H}_{2} \mathrm{O}_{2}$ and approximately $100 \mu \mathrm{g}$ of protein. $\mathrm{H}_{2} \mathrm{O}_{2}$ solution was added last to start the reaction and the initial increase in absorbance at $353 \mathrm{~nm}$ was recorded in Shimadzu spectrophotometer. The protein level of thyroid tissue was determined by the method of Lowry [12] using bovine serum albumin as a standard. The peroxidase activities obtained were expressed as change in optical density $(\Delta \mathrm{OD}) / \mathrm{min} / \mathrm{mg}$ protein).

\section{Measurement of Na+-K+ATPase activity}

$\mathrm{Na}+\mathrm{K}+\mathrm{ATPase}$ Activity was measured by a modification of the Esmann method [13]. The microsomal fraction of the thyroid gland homogenate was incubated in reaction mixtures of (a) $30 \mathrm{mmol}$ imidazole HCL, 130 $\mathrm{mmol} \mathrm{NaCl}, 20 \mathrm{mmol} \mathrm{KCl}, 4 \mathrm{mmol} \mathrm{MgCl} 2$ and (b) $1 \mathrm{Mm}$ ouabain at pH 7.4 for $60 \mathrm{~min}$ at $0{ }^{\circ} \mathrm{C}$. The reaction was initiated by adding $4 \mathrm{mmol}$ Tris-ATP at $37{ }^{\circ} \mathrm{C}$ and was stopped with the addition of $20 \%$ SDS. Inorganic phosphate $(\mathrm{Pi})$ thus liberated was determined by reading the absorbance at $850 \mathrm{~nm}$ in UVmini 1240, Shimadzu spectrophotometer, Japan by the method of Baginski et al. [14]. The enzyme activity was expressed in $\mathrm{n}$ moles of Pi liberated per hour per $\mathrm{mg}$ of protein from a standard curve of potassium dihydrogen phosphate.

\section{Protein estimation}

The protein content of samples was estimated following the method of Lowry et al. [12], using Bovine Serum Albumin (BSA) as standard.

Measurement of serum thyroxine (T4) and triiodothyronine (T3) and thyroid stimulating hormone (TSH)

The serum obtained from the experimental and control group of animals were used to measure T4 and T3 by Enzyme-Linked Immunoabsorbent assay (ELISA) kits obtained from RFCL Limited, India as per manufacturer's instructions.

TSH was measured via the same principle using kits obtained from Cusabio Biotech Limited, Rat TSH Kit following manufacturer's protocol.

\section{Urinary iodine estimation}

The animals were placed in metabolic cages and the collected urine samples of the animals were washed in a muffle furnace at $600{ }^{\circ} \mathrm{C}$ after digestion in strong alkali. Iodide was then assayed maintaining internal quality control by its catalytic action on the reduction of ceric ion $\left(\mathrm{Ce}^{2+}\right)$ to the cerous ion $\left(\mathrm{Ce}^{3+}\right)$ as per the method of Karmakar et al. [15].

\section{Histological study}

0n the day of the sacrifice, the thyroid glands of each group of animals were removed, weighed and fixed in formal (4\%) solution. The tissues were dehydrated by placing in gradually higher gradations of alcohol and embedded into paraffin to make blocks. Thyroid sections were cut using a microtome and collected on a slide. Sections were stained with haematoxylin and eosin and observed under a light microscope.

\section{Statistical analysis}

Results obtained were presented as mean \pm standard deviation. The differences if any between the groups were analyzed using Analysis of Variance (ANOVA) followed by Tukey's test. The level of significance was tested at $\mathrm{P}<0.05$. Statistical calculations were performed using Vassarstats online and MS Excel Office 2010 [16].

\section{RESULTS}

\section{Body weight}

Maximum percent gain of body weight was observed in thiourea treated group, while percent value of Bamboo-Shoots fed group also remained higher than the control group (table 1).

\section{Food consumption pattern}

Food consumption pattern was noted in each group for the entire period study and it was observed that feeding amounts remained almost similar in both experimental groups in view of the control group, with a non-significant decrease in the BS fed group as compared to control group (table 2).

Table 1: Changes in body weight of experimental after exposure to thiourea and bamboo-shoots respectively

\begin{tabular}{llll}
\hline Group & Initial body weight (g) & Gain of body weight (\%) & Final body weight (g) \\
\hline Control & $76.25 \pm 3.97$ & $(35.08)$ & $103 \pm 4.12$ \\
Thiourea treated & $74.44 \pm 3.02$ & $(59.08)^{\mathrm{a}}$ & $118.42 \pm 4.23$ \\
Bamboo-Shoot fed & $75.87 \pm 3.57$ & $(45.24)^{\mathrm{c}, \mathrm{b}}$ & $110.20 \pm 0.08$ \\
\hline
\end{tabular}

Data is represented as mean $\pm S D$ (standard deviation), $n=6$, Values significantly different by ANOVA (Analysis of Variance) $(P<0.05)$ are denoted by superscripts. a Control versus thiourea, b Control versus Bamboo-Shoots (BS) fed and c thiourea versus Bamboo-Shoots (BS) fed. 
Table 2: Changes in food consumption pattern after exposure to thiourea and bamboo-shoots respectively

\begin{tabular}{llll}
\hline Parameters & Groups & & \\
\cline { 2 - 4 } & Control & Thiourea treated & Bamboo-shoots fed \\
\hline Food intake/day/rat $(\mathrm{g})$ & $25 \pm 1.6$ & $25 \pm 2.1$ & $24 \pm 1.3$ \\
\hline
\end{tabular}

Data is represented as mean $\pm S D, n=6$, No significant difference found.

\section{SGOT and SGPT activities}

There was a minor increase in SGOT and SGPT levels in both experimental groups as compared to control, while greater but non-significant change occurred in thiourea administered animals (table 3)

\section{Thyroid gland weight}

The weight of the thyroid gland increased significantly $(\mathrm{P}<0.05)$ in both the goitrogen treated groups in comparison to control group with the maximum increase being noted in thiourea treated group. Thyroid gland weight of thiourea treated group was significantly greater than that of BS fed group (fig. 1)

Table 3: Changes in SGOT and SGPT activities after exposure to thiourea and bamboo-shoots respectively

\begin{tabular}{llll}
\hline Parameters & Control & Thiourea treated & Bamboo-shoots fed \\
\hline SGOT & $21.93 \pm 0.13$ & $22.58 \pm 0.18$ & $22.45 \pm 0.22$ \\
SGPT & $27.63 \pm 0.23$ & $28.72 \pm 0.31$ & $28.26 \pm 0.21$ \\
\hline
\end{tabular}

Data is represented as mean $\pm S D, n=6$, Values significantly different by ANOVA $(\mathrm{P}<0.05)$ are denoted by superscripts.

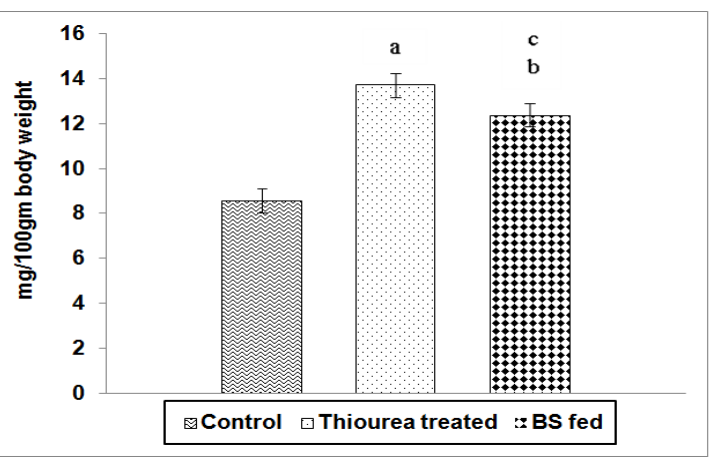

Fig. 1: Changes in thyroid weight after exposure to thiourea and bamboo-shoots respectively

Data is represented as mean $\pm S D$ (standard deviation), $n=6$, Values significantly different by ANOVA (Analysis of Variance) $(\mathrm{P}<0.05)$ followed by post-hoc tests are denoted by superscripts, a Control versus thiourea, b Control versus Bamboo-Shoots (BS) fed and c thiourea versus Bamboo-Shoots(BS)fed.

\section{TPO activity}

A significant decrease $(\mathrm{P}<0.05)$ in TPO activity was observed in both experimental groups in view of the control group. If the decrease in TPO activity of thiourea treated group is considered $100 \%$ then the relative decrease in TPO activity of BS fed animals was $73.10 \%$ of thiourea treated group. (fig. 2)

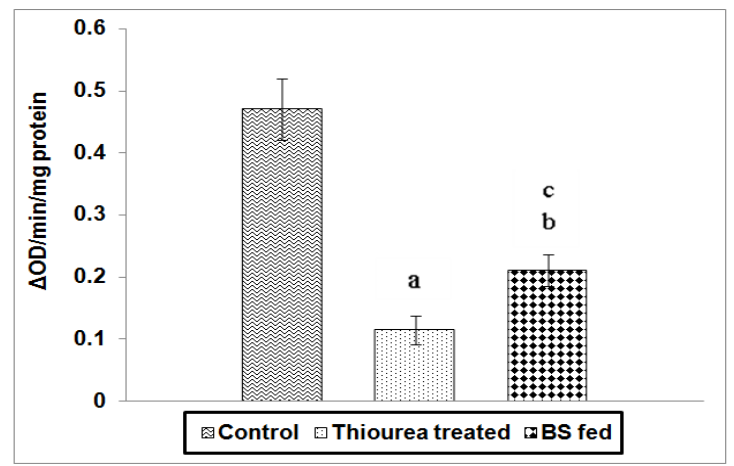

Fig. 2: Changes in thyroid peroxidase (TPO) activity after exposure to thiourea and bamboo-shoots respectively
Data is represented as mean $\pm S D$ (standard deviation), $n=6$, Values significantly different by ANOVA (Analysis of Variance) $(\mathrm{P}<0.05)$ followed by post-hoc tests are denoted by superscripts, a Control versus thiourea, $\mathrm{b}$ Control versus Bamboo-Shoots (BS)fed and c thiourea versus Bamboo-Shoots (BS)fed.

\section{$\mathrm{Na}+\mathrm{K}+\mathrm{ATPase}$ activity}

Compared to control group $\mathrm{Na}+\mathrm{K}+\mathrm{ATPase}$ activity was diminished significantly $(\mathrm{P}<0.05)$ in both thiourea treated and BS fed the group. However, decrease in BS fed group was $67.26 \%$ in comparison of considered $100 \%$ decrease of thiourea treated group (fig. 3).

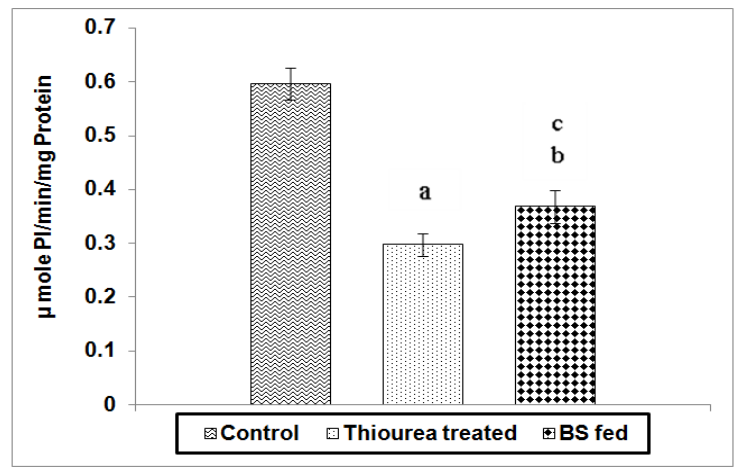

Fig. 3: Changes in Na-K ATPase activity after exposure to thiourea and bamboo-shoots respectively

Data is represented as mean $\pm S D$ (standard deviation), $n=6$, Values significantly different by ANOVA (Analysis of Variance) $(\mathrm{P}<0.05)$ followed by post-hoc tests are denoted by superscripts, a Control versus thiourea, b Control versus Bamboo-Shoots(BS) fed and c thiourea versus Bamboo-Shoots(BS) fed.

\section{Thyroid hormone levels}

Thyroid hormone levels were significantly low in both test groups in comparison to control. T3 levels decreased $41.36 \%$ in BS fed group relative to $100 \%$ decrease in thiourea treated group while T4 levels in BS fed group decreased to $53.80 \%$ of thiourea treated group levels (fig. 4).

TSH levels increased significantly in both experimental groups, with the highest upsurge in thiourea treated group. Considering the rise in thiourea treated group to be $100 \%$, the increase in BS fed group was $76 \%$ (fig. 5) 

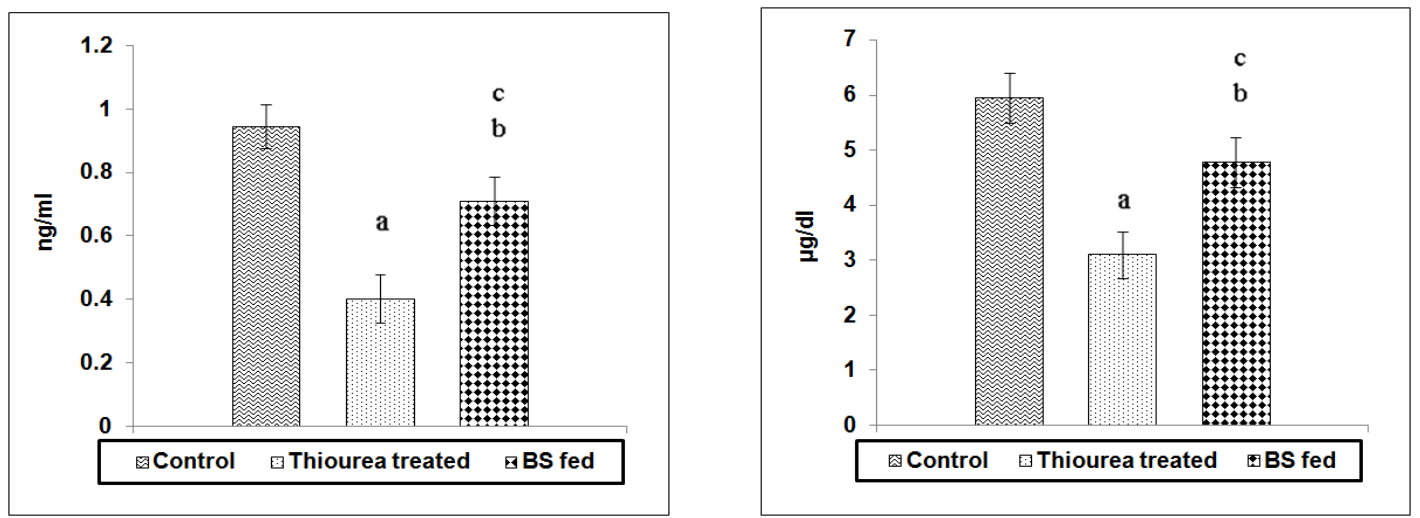

Fig. 4: Changes in triodothyronine (T3) and Thyroxine (T4) levels after exposure to thiourea and bamboo-shoots respectively

Data is represented as mean $\pm \mathrm{SD}$ (standard deviation), $\mathrm{n}=6$, Values significantly different by ANOVA (Analysis of Variance) $(\mathrm{P}<0.05)$ followed by post-hoc tests are denoted by superscripts, a Control versus thiourea, $b$ Control versus Bamboo-Shoots (BS)fed and $c$ thiourea versus Bamboo-Shoots (BS) fed.

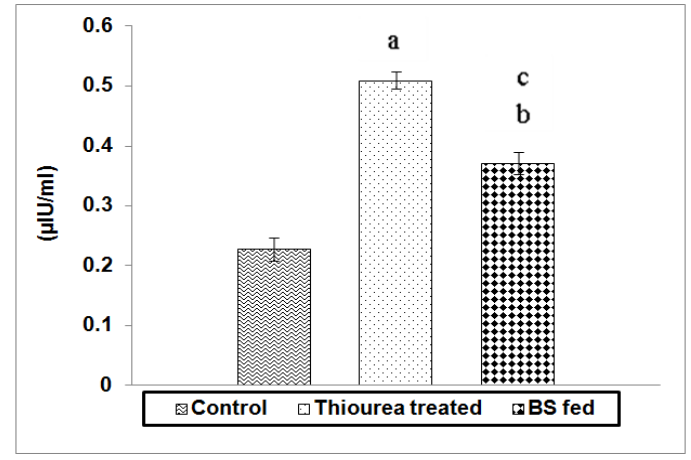

Fig. 5: Changes in thyroid stimulating hormone (TSH) levels after exposure to thiourea and bamboo-shoots respectively

Data is represented as mean $\pm \mathrm{SD}$ (standard deviation), $\mathrm{n}=6$, Values significantly different by ANOVA (Analysis of Variance) $(\mathrm{P}<0.05)$ followed by post-hoc tests are denoted by superscripts, a Control versus thiourea, $b$ Control versus Bamboo-Shoots (BS)fed and c thiourea versus Bamboo-Shoots (BS)fed.

\section{Urinary Iodine levels}

Urinary iodine levels showed a rise in both investigational groups in assessment, with the greatest significant increase observed in thiourea treated group (fig. 6).

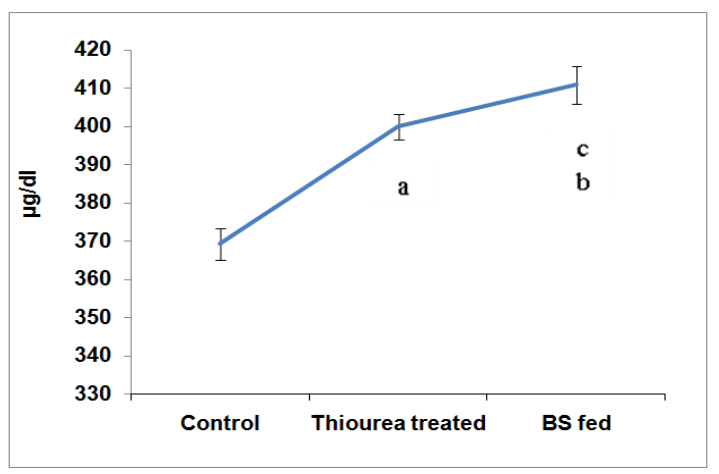

Fig. 6: Changes in urinary iodine levels after exposure to thiourea and bamboo-shoots respectively
Data is represented as mean $\pm \mathrm{SD}$ (standard deviation), $\mathrm{n}=6$, Values significantly different by ANOVA (Analysis of Variance) $(\mathrm{P}<0.05)$ followed by post-hoc tests are denoted by superscripts, a Control versus thiourea, $b$ Control versus Bamboo-Shoots (BS) fed and c thiourea versus Bamboo-Shoots (BS) fed.
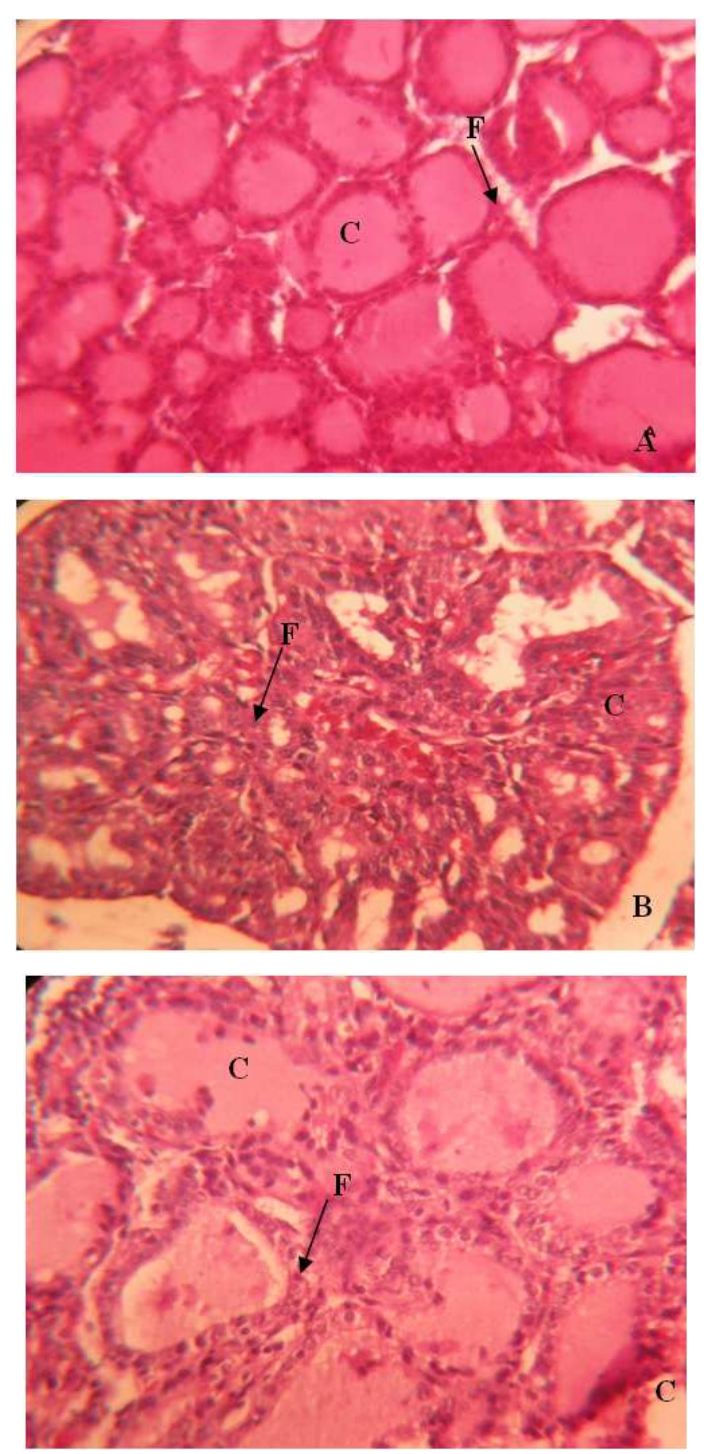

Fig. 7: Photomicrographs of $\mathrm{H}$ and $\mathrm{E}$ stained thyroid sections (400x) A) Control, B), Thiourea treated, C) Bamboo-Shoots fed, C $=$ Colloid, $\mathrm{F}=$ Follicle 


\section{Histological studies of thyroid}

Normal thyroid histology showed even epithelium and regularly shaped cells filled with colloid. Histological comparison of BS fed animal's thyroid to normal revealed general thyroid follicular cell disruption and microcytic infiltration. Follicular size increased markedly resulting in rupture of follicles and evacuation of follicular colloid materials indicating a discernable hypertrophy of gland. Thiourea treated animal's glands exhibit complete abolition of normal histoarchitecture with definite changes in the colloidal area. Congestion of follicle due to increase in number, resorption of colloidal materials, hyperplasia with huge folding and papillae on epithelium were other distinct features seen (fig. 7).

\section{DISCUSSION}

Even with the advent and prevalent usage of anti-thyroidal drugs since a protracted amount of time, hyperthyroidism and other related disorders remain a common problem worldwide with a greater proportion of negative impacts of such drugs coming to light. Presently, however, several natural food products emerging as nutraceuticals are being used worldwide to treat thyroid disorders. Although several vegetables of the brassicae family like radish, cabbage, brussel sprouts, turnips, mustard and rapeseed, etc are known for their goitrogenic activity [17], a broad database of comparative goitrogenic potential between commercially available known anti-thyroidal drugs used to treat hyperthyroidism and having other environmental exposure with such natural goitrogens has not been compiled. This study has thus been designed simplistically to compare the goitrogenic potentiality of such a natural goitrogen bamboo-shoots, which on daily consumption reportedly causes endemic goiter in Manipur, India [5] and a well-known chemical anti-thyroidal agent thiourea which is the major constituent of several synthetic drugs used in treatment of hyperthyroidism like methimazole, PTU [18], etc

BS was fed in the amount such that the total amount of reported antithyroidal components in it was approximately equivalent to a thiourea dose of $6 \mathrm{mg} / 100 \mathrm{~g}$ of body weight. Food consumption pattern for both experimental groups remained nearly similar to control animals indicating almost comparable intake of both antithyroidal exposures.

Serum SGOT and SGPT values did not vary significantly between the control and experimental groups representing the absence of toxicity occurrence [19]. However, values for thiourea treated animals remained elevated as compared to BS fed animals expressing manifestation of a greater harmful outcome.

To conform with the well-known reality that there is increase in body weight in hypothyroidism [20], both groups of experimental animals exposed to anti-thyroidal treatment namely thiourea and BS feeding exhibited a percent gain in body weight as compared to the normal animals, however, a greater percent increase was seen in thiourea treated group leading to the conclusion that probably the degree of hypothyroid induction was much greater by thiourea in comparison to BS. In absolute association to this, the maximum amount of significant gain in thyroid weight was also noted in thiourea treated animals, followed by BS fed animals in view of the control animals. Previous studies with both thiourea [21] and other natural goitrogens similar to BS like cassava [22] have yielded similar results individually; however, a comparison was done only in this study, indicative of the greater antithyroidal capacity of thiourea.

Histological plates of the thyroid glands of both the treated groups revealed prominent hypertrophic and hyperplastic changes, while there was much greater histoarchitecture disruption and extreme follicle congestion along with rupture and papillae on the epithelium in the thiourea treated animals. Microcystic infiltration was also noted in the BS fed group. At a glance, however, it is very apparent that the disruptive changes are much greater in the thiourea treated group, indicative of the much greater efficacy of the synthetic drug against the natural goitrogen. Similar disruptive changes have been found in ethylene thiourea fed rats [23] and also in another natural goitrogen like cassava, radish fed animals [24].

The aberrations in the thyroid morphology caused due to the exposure to the goitrogens contributed to the significant decrease in T3 and T4, in addition, a complementary increase in TSH level in both treated groups as equated with the control. T3 and T4 levels decreased near to $50 \%$ and TSH increased to $76 \%$ in BS fed animals in comparison of levels in thiourea fed animals. T3 and T4 lie in direct feedback control of TSH via the pituitary-thyroid axis and affect each other inversely [25]. As previously mentioned, the enlargement of the gland can be expected to be in direct connection with the hypersecretion of TSH leading to an underactive thyroid.

Suppressed thyroid hormone levels were indicative of a decrease in their synthesizing enzyme which was validated by testing the levels of thyroid peroxidase (TPO) activity of all groups. TPO plays a pivotal role in $\mathrm{T} 3$ and $\mathrm{T} 4$ synthesis being the primary enzyme in association with thyroglobulin in iodide organification and coupling [26]. Both experimental groups confirmed to a decline in TPO activity in analysis with the control group, nonetheless, thiourea treated animals in concordance with all previous parameters revealed the greatest decrease in TPO activity. Considering this decrease to be $100 \%$ in relation to the control, the decrease in BS fed animals was $73.10 \%$. Thiourea and its derivatives are known to cause TPO inhibition by interfering with TPO-catalyzed iodine formation with related oxidative metabolism. Synthetic drugs reportedly can act on peroxidase and/or the molecular iodine which may be produced by oxidation of iodides (2I-—》2 $\longrightarrow 2 \mathrm{I}+)$ to cause disruption [27]. Previous studies in Bambusa arundinacea subtype of BS have also been reported to interfere with TPO activity in vivo, although the exact mechanism remains unidentified [8].

$\mathrm{Na}+\mathrm{K}+\mathrm{ATPase}$ is located in the basolateral membrane of the thyroid follicular cells and in association with sodium iodide symporter (NIS) is responsible for follicular iodide uptake and transport [28]. In this study, Na+-K+ATPase activity decreased significantly in both investigational groups relative to the control group, the greater decrease was seen in thiourea treated group. In comparison to thiourea treated group, the decrease in BS fed group was $67.26 \%$. Thiourea along with its spin-off products like tetramethylthiourea, ethylenethiourea are well-acknowledged inhibitors of iodide uptake via NIS, similarly, in the association, a complementary decrease in Na+$\mathrm{K}+\mathrm{ATPase}$ activity can be predicted, a likely explanation for suppression of $\mathrm{Na}+-\mathrm{K}+\mathrm{ATPase}$ activity by the goitrogen exposures in this study [29]. Earlier studies with other thiocyanate exposure have reported a decrease in $\mathrm{Na}+-\mathrm{K}+\mathrm{ATPase}$ activity, explaining the decrease in BS fed group as BS releases thiocyanate on breakdown [30].

Urinary iodine level is a suggestive marker of iodine nutritional status as a high percent (over 90) of iodine consumed is excreted in the urine. Greater urinary iodine concentration reflects more iodine efflux and less utilization in the gland [31]. Thiourea competitively inhibits iodine uptake by severely reducing the activity of NIS and causing iodine complexation during iodide oxidation [29]. On the other hand, the antithyroidal constituents in BS like cyanogenic glycosides, glucosinolates break down to form thiocyanate, in addition to the basic thiocyanate content of the vegetable [8]. Thiocyanate is a wellestablished inhibitor of iodide transporter in the thyroid but is more potent in increasing iodide efflux which is reflected in increased urinary iodine levels of consumption of such vegetables [32]. Similarly, in this study, increased urinary iodine levels were found in both experimental groups, but a greater enhancement was seen in thiourea treated group elucidating that less iodine was utilized and up taken in this group leading to decrease in $\mathrm{T} 3$ and $\mathrm{T} 4$ synthesis in turn. Thiocyanate from the BS also inhibited iodine uptaken but to a much lesser extent in comparison to thiourea.

\section{CONCLUSION}

Thiourea in comparison to BS has much severe down regulatory activities in the thyroid gland, at all stages of hormone synthesis that include iodide uptake, iodide organification and coupling of iodotyrosine molecules by decreasing the activities of concerned enzymes resulting marked alteration thyroid morphology as well as physiology. However, BS has the potentiality to cause significant inhibition on those regulatory elements but with relatively less severity and toxicity. The overall results reveal that the efficacy of BS in suppressing thyroid activities is not less than a proximate average of $50 \%$ of thiourea. In retrospection it can be thus proposed that the antithyroidal components in BS have the potentiality to cause a diminution of thyroid activity but with less toxic implications that in 
turn can be formulated into antithyroidal drugs of natural origin in long run with less side effects. Further studies are obligatory to bring about the comparison of the molecular mechanism and potentially negative implications of the two materials which are ongoing in the investigator's laboratory.

\section{ABBREVIATION}

T3-Triiodothyronine, T4-Thyroxine, TSH-Thyroid Stimulating Hormone, SGOT-Serum glutamic-oxaloacetic transaminase), SGPTSerum glutamic pyruvic transaminase, BS-Bamboo Shoots, SDStandard Deviation, ANOVA-Analysis of Variance, TPO-Thyroid Peroxidase, PTU-Propylthiouracil.

\section{ACKNOWLEDGEMENT}

Authors are thankful to BI (92) research grant of Department of Physiology, University of Calcutta. Deotima Sarkar gratefully acknowledges financial assistance from DST INSPIRE Fellowship Scheme, Govt. of India.

\section{AUTHOR CONTRIBUTION}

Deotima Sarkar: Data collection and analysis, drafting article, writing manuscript

Arijit Chakraborty: Data collection and analysis, critical revision of the article

\section{Chandrima Bhattacharya: Data collection}

\section{Laishram Hemchandra Singh: Sample and data collection}

Prof. Amar K Chandra: Design of the work, data analysis, critical revision of the article, final approval of the version to be published.

\section{CONFLICT OF INTERESTS}

The authors declared no potential conflicts of interest with respect to the authorship, research, or publication of this article.

\section{REFERENCES}

1. Manna D, Roy G, Mugesh G. Antithyroid drugs and their analogues: synthesis, structure, and mechanism of action. Acc Chem Res 2013;46:2706-15.

2. Criteria Group for Occupational Standards. Scientific basis for Swedish occupational standards XXII. Consensus report for Diisocyanate (TDI), Diphenylmethane Diisocyanate (MDI), Hexamethylene Diisocyanate (HDI). Arbeteoch Halsa 2001;20:60-88.

3. Hosoya T. Effect of various reagents including antithyroid compounds upon the activity of thyroid peroxidase. J Biochem 1963;53:381-8.

4. Morgans M. Toxic effects of thiourea, thiouracil, methyl thiouracil, and aminothiazole in thyrotoxicosis. Lancet 1947;249:519-21.

5. Chandra AK, Singh L, Ghosh S, Pearce E. Role of bamboo-shoot in the pathogenesis of endemic goiter in Manipur, North East India. Endocr Pract 2012;19:36-45.

6. Chandra AK, Mukhopadhyay S, Lahari D, Tripathy S. Goitrogenic content of Indian cyanogenic plant foods and their in vitro anti-thyroidal activity. Indian J Med Res 2004;119:180.

7. Chakraborty A, Mandal J, Mondal C, Sinha S, Chandra AK. Effect of excess iodine on oxidative stress markers, steroidogenicenzyme activities, testicular morphology, and functions in adult male rats. 2015. Biol Trace Elem Res 2016;172:380-94.

8. Chandra AK, Ghosh D, Mukhopadhyay S, Tripathy S. Effect of bamboo shootBambusaarundinacea (Retz.) Wild on thyroid status under conditions of varying iodine intake in rats. Indian J Exp Biol 2004;42:781-6.

9. Material Safety Datasheet on thiourea. Available from: www.clayton.edu/portals/690/chemistry/inventory/MSDS\%2 0Thiourea.pdf. [Last accessed on 19 Apr 2017]

10. Cooper DS. Antithyroid drugs. N Engl J Med 2005;352:905-17.
11. Alexander NM. Assay procedure for thyroid peroxidase. Anal Biochem 1962;4:341-5.

12. Lowry $\mathrm{OH}$, Rosebrough NJ, Farr AL, Randall RJ. Protein measurement with the Folin phenol reagent. J Biol Chem 1951;193:265-75.

13. Skou JC, Esmann M. Preparation of membrane Na+, K+-ATPase from rectal glands of Squalusacanthias. Methods Enzymol 1988;156:43-6.

14. Baginski ES, FoaPP, Zak B. Determination of phosphate: a study of labile organic phosphate interference. Clin Chim Acta 1967;15:155-8.

15. Ohashi T, Yamaki M, Pandav CS, Karmarkar MG, Irie M. Simple microplate method for determination of urinary iodine. Clin Chem 2000;46:529-36.

16. Stats V. Website for Statistical Computation; 2015.

17. Michajlovskij N, Sedlak J, Kostekova O. Content of naturally occurring goitrogens in boiled plants of the brassica family. Endocrinol Exp 1969;4:51-62.

18. Emiliano AB, Governale L, Parks M, Cooper DS. Shifts in propylthiouracil and methimazole prescribing practices: antithyroid drug use in the United States from 1991 to 2008. J Clin Endocrinol Metab 2010;95:2227-33.

19. Tresina PS, Sornalakshmi V, Paulpriya K, Mohan VR, Arumugasamy K. Hepatoprotective effect of Hedyotisleschenaultiana dc, ethanol extract in ccl4 induced hepatotoxicity in wistar rats. Asian J Pharm Clin Res 2014;7:287-90.

20. Ray G, Fisher D, Chopra I. Relation of thyroid hormones to body-weight. Lancet 1976;307:1206-8.

21. Mackenzie CG, MacKenzie JB. Effect of sulfonamides and thioureas on the thyroid gland and basal metabolism. Endocrinology 1943;32:185-209.

22. Chandra AK, Ghosh D, Mukhopadhyay S, Tripathy S. Effect of cassava (Manihotesculentacrentz) on thyroid status under conditions of varying iodine intake in rats. Afr J Tradit Complementary Altern Med 2006;3:87-99.

23. Graham SL, Davis KJ, Hansen WH, Graham CH. Effects of prolonged ethylene thiourea ingestion on the thyroid of the rat. Food Cosmet Toxicol 1975;13:493-9.

24. Chandra AK, Mukhopadhyay S, Ghosh D, Tripathy S. Effect of radish (Raphanussativus Linn.) on thyroid status under conditions of varying iodine intake in rats. Indian J Exp Biol 2006;44:653.

25. Faber J, Kirkegaard C, Rasmussen B, Westh H, Busch-Sørensen M, Jensen IW. Pituitary-thyroid axis in critical illness. J Clin Endocrinol Metab 1987;65:315-20.

26. Ruf J, Carayon P. Structural and functional aspects of thyroid peroxidase. Arch Biochem Biophys 2006;445:269-77.

27. Doerge DR, Takazawa RS. Mechanism of thyroid peroxidase inhibition by ethylene thiourea. Chem Res Toxicol 1990;3:98-101.

28. Ewart HS, Klip Amifu. Hormonal regulation of the Na (+)-K (+)ATPase: mechanisms underlying rapid and sustained changes in pump activity. Am J Physiol Cell Physiol 1995;269:295-311.

29. Raby C, Lagorce JF, Jambut-Absil AC, Buxeraud J, Catanzano G. The mechanism of action of synthetic antithyroid drugs: iodine complexation during oxidation of iodide. Endocrinology 1990;126:1683-91.

30. Mondal C, Sinha S, Chakraborty A, Chandra AK. Studies on Goitrogenic/Antithyroidal potentiality of thiocyanate, catechin and after concomitant exposure of thiocyanate-catechin. Int J Pharm Clin Res 2016;8:108-16.

31. Chakraborty A, Mondal C, Sinha S, Mandal J, Chandra AK. Amiodarone-induced oxidative stress in stress-vulnerable organs of adult male rats. Asian J Pharm Clin Res 2014;4:177-83.

32. Chandra AK. Iodine, thiocyanate and the thyroid. Biochem Pharmacol 2015;4:3.

\section{How to cite this article}

- Deotima Sarkar, Arijit Chakraborty, Chandrima Bhattacharya, Laishram Hemchandra Singh, Amar K Chandra. Exploration of the goitrogenic/antithyroidal potentiality of bamboo-shoots in relation to thiourea. Int J Pharm Pharm Sci 2017;9(10):7-12. 